\title{
Resistencias contra el neoliberalismo: una conceptualización de su ejercicio entre lo local y lo global
}

\author{
Carolina Cepeda-Másmela*
}

\section{ReSUmen}

Desde la década de 1970 se han implementado políticas neoliberales que afectan distintas esferas de la vida social. Por ello, definir el neoliberalismo como una forma de racionalidad política resulta útil para entender sus variadas manifestaciones y efectos, así como los distintos tipos de resistencia que se construyen en su contra.

Este artículo hace una propuesta conceptual desde un marco neogramsciano en relaciones internacionales, que permite entender las resistencias contra el neoliberalismo como prácticas locales y globales diversas que retan el orden establecido y cuestionan su carácter hegemónico. Todo esto en un proceso de cambio social que abarca tanto experiencias individuales como globales, que confluyen en el denominado "movimiento alterglobalización". Para tales fines, en primer lugar, se caracteriza el neoliberalismo como una forma de racionalidad política, mostrando sus efectos más allá de las dimensiones socioeconómicas; en segundo lugar, se conceptualizan las resistencias en su contra como se ha descrito anteriormente; en tercer lugar, se presenta un análisis del movimiento alterglobalización, entendiendo que no es un actor unificado sino un proceso de cambio social apuntalado por la diversidad; y, finalmente, se presentan una serie de conclusiones que resaltan la importancia académica y política de esta perspectiva.

\section{Palabras clave}

Resistencias contra el neoliberalismo; movimiento alterglobalización; diversidad; racionalidad política; neoliberalismo.

\section{TITLE}

Resistances against neoliberalism: a conceptualization of its exercise between the local and the global

\begin{abstract}
Since the 1970s, the implementation of neoliberal policies has hit different spheres of social life. Therefore, defining neoliberalism as a form of political rationality is useful to understand its various manifestations and effects, as well as the different types of resistance against it. This article makes a conceptual proposal from a neo-Gramscian framework in international relations, which makes it possible to understand the resistances against neoliberalism as diverse local and global practices that challenge the established order and question its hegemonic character. All this in a process of social change that includes both individual and global experiences, which converge in the so-called "alter-globalization movement". For such purpose, the article follows this structure: first section characterizes neoliberalism as a form of political rationality, showing its effects beyond socio-economic dimensions. Second section conceptualizes resistance against it as described above. Third section analyses the alter-globalization movement understanding it is not a unified actor but a process of social change propped up by diversity. Finally, there is a series of conclusions that highlight the academic and political importance of this perspective.
\end{abstract}

\section{KeYWORDS}

Resistances against neoliberalism; alter-globalization movement; diversity; political rationality; neoliberalism.

\section{* Carolina CEPEDA- MÁSMELA Profesora del De- partamento de Relaciones Interna- cionales de la Pon- tificia Universidad Javeriana, Bogotá. Es politóloga, ma- gíster en estudios políticos y doctora en ciencia política. Su trabajo aca- démico se centra en las resistencias contra el neolibera- lismo. E-mail: ca- rocep@gmail.com, ycepeda@javeriana. edu.co.}

Recibido:

15/03/2018

Aceptado:

18/09/2018

DOI:

http://dx.doi. org/10.15366/relacionesinternacionales2018.39.004 


\section{ntroducción}

La instauración del neoliberalismo tiene efectos negativos que van desde el desempleo y empobrecimiento de distintas capas de población, hasta la interiorización de principios como la eficiencia y la competencia para regir el comportamiento individual. Sin embargo, la expansión de la globalización neoliberal que está implícita en ello también ha generado motivaciones asociadas a sus efectos negativos y oportunidades para que se organicen diferentes formas de resistencia en su contra ${ }^{1}$, debido tanto a los contextos de precariedad que genera, como a las herramientas e innovaciones en interconexión. Es posible observar cómo distintas formas de resistencia se organizaron desde comienzos de la década de los noventa para denunciar los efectos negativos del neoliberalismo, al tiempo que demandaban una serie de medidas de protección por parte de sus respectivos estados y de algunas organizaciones internacionales ${ }^{2}$ y se comprometían con la búsqueda de alternativas.

El objetivo de este artículo es proporcionar un marco conceptual que permite analizar tales resistencias, entendiéndolas como prácticas locales y globales que retan el orden establecido y cuestionan su carácter hegemónico, en un ejercicio que evidencia la existencia de una pluralidad de alternativas que confluyen en el denominado movimiento alterglobalización. Para ello, se presenta una caracterización del neoliberalismo como una forma de racionalidad política, que permite ver sus efectos más allá de las dimensiones estrictamente sociales y económicas. En un segundo momento, se conceptualizan las resistencias contra el neoliberalismo teniendo en cuenta los aportes de la escuela neogramsciana en relaciones internacionales, los estudios poscoloniales y la teoría de los movimientos sociales. En tercer lugar, se ofrece una descripción del movimiento alterglobalización como proceso de cambio social, considerando los distintos actores que toman parte en él, sus expresiones y su trayectoria. Finalmente, se presentan una serie de conclusiones que resaltan la importancia académica y política de esta perspectiva.

\section{Racionalidad neoliberal}

Hay distintas definiciones de neoliberalismo en la literatura ${ }^{3}$ que resaltan alguna de sus muchas dimensiones: paquete de políticas públicas ${ }^{4}$, ideología, gubernamentalidad ${ }^{5}$ o proyecto de restauración del poder de clase ${ }^{6}$. Estas distintas aproximaciones dan cuenta de su complejidad y permiten identificar aquellos aspectos que podrían constituir su base. Sin embargo, dentro de este conjunto aparece la definición que propone Wendy Brown ${ }^{7}$ : una forma de racionalidad política. Esta definición permite entenderlo como un fenómeno amplio que transforma la

1 GILLS, Barry, "Introduction: Globalization and the Politics of Resistance" en GILLS, Barry (ed.), Globalization and the Politics of Resistance MacMillan Press, Londres, 2000, pp. 3-11.

2 POLANYI, Karl, La Gran Transformación: los Orígenes Políticos y Económicos de Nuestro Tiempo, Fondo de Cultura Económica, México, 2003, pp. 123-135.

3 AUERBACH, Nancy, "The meanings of neoliberalism" en ROY, Raven, DENZAU, Arthur \& WILLET, Thomas (eds.), Neoliberalism. National and Regional Experiments with Global Ideas, Routledge, Nueva York, 2007, pp. 26-50.

4 RESTREPO, Dario, "De la Falacia Neoliberal a la Nueva Política" en La Falacia Neoliberal. Críticas y Alternativas, Universidad Nacional de Colombia, Bogotá, 2003, pp. 19-40.

5 STEGER, Manfred., \& ROY, Ravi, Neoliberalism: a Very Short Introduction, Oxford University Press, Nueva York, 2010.

6 HARVEY, David, Breve Historia del Neoliberalismo. Akal, Madrid, 2007.

7 BROWN, Wendy, "Neoliberalism and the End of Liberal Democracy" en Theory and Event, Vol. 7, no 1, 2003. BROWN, Wendy, "American Nightmare. Neoliberalism, Neoconservatism and De-democratization" en Political Theory, Vol. 34, no 6, 2006, pp. 690-714. 
política, la economía, la sociedad y los individuos; al tiempo que contribuye a indagar por sus distintos efectos y por la diversidad de formas que adoptan las resistencias en su contra.

Siguiendo el argumento de Brown ${ }^{8}$ el neoliberalismo se manifiesta tanto en la política y la economía, como en la organización social y en la vida cotidiana de los individuos, por lo que es más apropiado entenderlo como una forma de racionalidad política que:

"Lleva un análisis social en el que, cuando se despliega como una forma de gubernamentalidad, alcanza desde el alma de los sujetos-ciudadanos hasta la política educativa y las prácticas de imperio. La racionalidad neoliberal, mientras destaca el mercado, no está sólo o al menos primariamente enfocada en la economía; al contrario, implica extender y diseminar los valores del mercado a todas las instituciones y la acción social"'.

Las principales características de esta forma de racionalidad política pueden resumirse en que todas las acciones humanas e institucionales se producen como acciones empresariales; hay un reconocimiento de la artificialidad del mercado y la racionalidad económica, por lo que deben ser construidos y organizados por las instituciones políticas sin que ello implique un control del mercado por parte del estado; y, la racionalidad económica llega a terrenos no económicos y prescribe la conducta de los ciudadanos. En esta racionalidad, la legitimidad del estado está dada por su capacidad de respuesta a las necesidades del mercado, hecho que pasa por tener como criterio en la toma de decisiones el análisis costo-beneficio.

El valor de esta concepción del neoliberalismo radica en que es posible comprenderlo como un fenómeno amplio que transforma la política, la economía, la vida social y los individuos, lo que permite indagar por sus efectos más allá de las condiciones materiales de las personas y comprenderlos en un sentido mucho más amplio. También facilita el análisis de las diferentes formas de resistencia que se han generado en torno a la globalización neoliberal, la compleja gama de reivindicaciones que estas encierran y la pluralidad de estrategias utilizadas para enfrentarlo. Estas resistencias van mucho más allá del ámbito exclusivamente económico asociado a demandas materiales y, al contrario, se enmarcan en discursos y prácticas que comprenden diferentes ámbitos de la vida social en los que el neoliberalismo ha tenido algún tipo de efecto.

Los efectos del neoliberalismo se observan en diferentes esferas de la vida y se pueden sintetizar en el aumento de la desigualdad y la concentración de la riqueza, la exclusión social y política de los sectores tradicionalmente marginados y los empobrecidos a causa de las políticas neoliberales, la profundización de problemáticas políticas y económicas anteriores, la consolidación de conceptos como eficiencia y competitividad como valores sociales e individuales, la amenaza a los vínculos de solidaridad y el tejido social, y el poder creciente de las corporaciones transnacionales en detrimento de los derechos de ciudadanía.

Paradójicamente estos mismos efectos y algunas de las transformaciones implícitas en la globalización también crearon oportunidades para la recuperación y el fortalecimiento

\footnotetext{
8 BROWN, Wendy, "American Nightmare...' op.cit.
}

9 BROWN, Wendy, "Neoliberalism and the...' op.cit. 
de formas de organización social solidarias. Si bien es posible afirmar que uno de los impactos del neoliberalismo puede rastrearse en las condiciones materiales, que no pueden entenderse a primera vista como una oportunidad para la movilización social, los actores sociales son capaces de resignificar algunos elementos de estas condiciones y transformarlos en oportunidades para sí mismos y para otras organizaciones ${ }^{10}$; en ello, la imaginación es fundamental. Por otro lado, las innovaciones tecnológicas, los medios de comunicación y los flujos migratorios ofrecen posibilidades para la organización de movimientos sociales y otro tipo de colectivos, debido a que hay una mayor disponibilidad de información sobre las problemáticas y los acontecimientos en diferentes regiones del mundo, lo que facilita el acercamiento, el conocimiento y el posicionamiento frente a diversas problemáticas globales, nacionales y locales, y la construcción de vínculos de solidaridad.

\subsection{Efectos}

Uno de los principales efectos del neoliberalismo ha sido el aumento del desempleo como consecuencia de las políticas de flexibilización laboral. Ejemplo de ello es América Latina que muestra incrementos sustanciales en dos momentos concretos, 1982-1984 y 1992-2004, que coinciden con las dos fases de la implementación de políticas neoliberales en la región. Según datos de la Comisión Económica para América Latina y el Caribe- CEPAL, esto se manifestó con particular fuerza en el primer periodo en países como Colombia $(13,2 \%)$, Chile $(15,3 \%)$ y Ecuador $(10,6 \%)$, y en el segundo periodo en Argentina $(17,3 \%)$, Colombia $(17,1 \%)$ y Venezuela (18\%).

El aumento de la pobreza, por su parte, también ha sido significativo en la región. De acuerdo con los datos consignados en la CEPAL, esta ha aumentado 4 puntos porcentuales desde 1980, mientras que la pobreza extrema muestra un aumento menos pronunciado (de $18,6 \%$ a $19,4 \%$ entre 1980 y 2002). Esto es aún más preocupante si se tienen en cuenta, por un lado, el crecimiento demográfico de los países de la región y, por el otro, lo que ello significa en términos de número de personas en estado de pobreza y de pobreza absoluta.

Esto es todavía más dramático si se tiene en cuenta que, como lo reporta la CEPAL, hay un aumento significativo en la concentración de la riqueza, especialmente en las zonas rurales donde las políticas neoliberales se materializaron durante la década de los noventa a través de la eliminación de formas de propiedad colectiva, tratados y acuerdos de libre comercio, y la tecnificación de la producción agrícola, sobre todo en países como México y Brasil. Es importante señalar una disminución en la concentración de la riqueza desde 2002, especialmente en países como Argentina, Bolivia y Brasil, en donde se han implementado políticas sociales orientadas hacia la redistribución del ingreso a través de programas como "Argentina Trabaja", "Bolsa Familia" en Brasil y el "Bono Juancito Pinto" en Bolivia. Este último efecto, por supuesto, no es exclusivo del Tercer Mundo. Según datos de la OCDE también se ha manifestado en algunos países del primer mundo que adoptaron las políticas neoliberales, como Estados Unidos y el Reino Unido desde la década de 1980.

Estos efectos se han dado en un marco de privatización de empresas públicas y de mercantilización de recursos naturales como el agua o la tierra, bienes y servicios sociales

\footnotetext{
10 TARROW, Sidney, The New Transnational Activism, Cambridge University Press, Nueva York, 2007.
} 
como la salud y la educación, y elementos de la vida social como la cultura, que no han sido construidos con el fin de ser transados en el mercado. Estas privatizaciones y procesos de mercantilización han conducido a un aumento del poder del capital transnacional que se fundamenta en la dependencia hacia las corporaciones en tanto la mayoría de los bienes que se consumen son producidos por ellas ${ }^{11}$.

Dentro del ranking de las cien compañías transnacionales no financieras con mayores activos en el exterior realizado por la UNCTAD anualmente, es posible encontrar en el periodo 1997-2012 compañías dedicadas a industrias diversas: explotación petrolera (Exxon Mobile, Estados Unidos y British Petroleum, Reino Unido; química/farmacéutica, (Roche, Suiza y Bayer, Alemania); editorial (Thomson Corporation, Canadá); explotación minera (AngloAmerican, Reino Unido); bienes de lujo (Louis Vuitton, Francia), provisión de servicios públicos (Electrecité, Francia); alimentos (Nestlé, Suiza); automotor (Volkswagen Group, Alemania); restaurantes (McDonalds, Estados Unidos); comida, bebida y tabaco (British American Tobacco, Reino Unido); y, comercio (Itocho Corporation, Japón), entre muchas otras.

Esa presencia en diferentes industrias se traduce también en influencia en distintas esferas de la vida social, por lo que las corporaciones transnacionales tienen cada vez más la potestad de intervenir en sus mercados, en las reglas de juego que los organizan, en la legislación estatal y, especialmente, en las preferencias de los consumidores. Así, las distintas corporaciones recurren a campañas publicitarias y promoción de sus productos para crear una demanda entre los consumidores, contrario al postulado del liberalismo clásico según el cual los productores responden a las demandas de los consumidores ${ }^{12}$.

Las compañías transnacionales toman el estado ${ }^{13}$ y se produce una alianza perversa entre actores de ambas esferas gracias a lo cual se ha configurado lo que Naomi Klein denomina un sistema corporativista, en el que los límites entre este y el sector privado han sido casi eliminados, produciéndose una gran transferencia de la riqueza pública hacia el sector privado ${ }^{14}$. En este contexto, esta racionalidad se afianza a través de lo que Stephen Gill (2008) denomina neoliberalismo disciplinario que requiere de una reestructuración de las formas estatales y de la política internacional que tiene lugar a través del nuevo constitucionalismo, entendido como "el proyecto político para intentar hacer del liberalismo transnacional, y si es posible del capitalismo democrático liberal, el único modelo para el desarrollo futuro"15. En otras palabras, arreglos institucionales tales como la creación de bancos centrales independientes, leyes de presupuesto balanceado, reformas económicas y políticas sociales enmarcadas dentro de los dictámenes neoliberales; todo ello en contraposición al constitucionalismo tradicional donde se contemplan derechos de ciudadanía de primera, segunda y tercera generación ${ }^{16}$.

\footnotetext{
${ }^{11}$ HERTZ, Noreena, The Silent Takeover. Global Capitalism and the Death of Democracy, The Free Press, Nueva York, 2001.

${ }^{12} \mathrm{CROUCH}$, Collin, The Strange Non-Death of Neoliberalism, Polity Press, Cambridge, 2011.

13 HERTZ, Noreena, The Silent Takeover..., op.cit.

${ }^{14}$ KELIN, Naomi, La Doctrina del Shock, Paidós, Buenos Aires, 2010.

15 GILL, Stephen, Power and Resistance in the New World Order, Palgrave McMillan, Nueva York, 2008, p. 139.

${ }^{16}$ GILL, Stephen, "Introduction: Global Crises and the Crisis of Global Leadership" en GILL, Stephen (ed.), Global Crises and the Crisis of Global Leadership, Cambridge University Press, Cambridge, 2012, pp. 21-37.
} 
El efecto inmediato de este nuevo constitucionalismo es que dificulta la implementación de modelos alternativos dado que "confiere derechos privilegiados de ciudadanía y representación al capital corporativo, mientras constriñe el proceso de democratización que ha implicado luchas por representación durante cientos de años"17, por lo que los canales institucionales para promover las transformaciones políticas quedan prácticamente anulados. Así el estado resulta ser un actor fundamental dentro de la racionalidad neoliberal: "aunque el neoliberalismo es frecuentemente identificado con la retirada del estado (...), en realidad los Estados neoliberales siempre han estado activamente implicados en la construcción de identidades y subjetividades y en el moldeamiento de cuerpos y mentes" ${ }^{\prime \prime 18}$. Se pasa entonces de un estado intervencionista en la economía a un estado que interviene ahora en la construcción de sujetos sociales y los disciplina a partir de los criterios de la economía de mercado.

La racionalidad neoliberal transforma entonces la definición de la democracia y de sus prácticas. La democracia en el contexto neoliberal se define a partir de "un estado y sujetos organizados por la racionalidad del mercado"19, lo que implica transformaciones en la organización social, la vida cotidiana y los hábitos de consumo. Valores fundamentales de la democracia liberal como la igualdad ante la ley, la representación y el bien común, quedan desplazados por criterios como la maximización de beneficios, que terminan por guiar las acciones sociales de una manera cada vez más individualizada, mercantilizando procesos democráticos como las elecciones y creando algunos dilemas en los que los "otros" son percibidos como amenazas a los intereses propios, por lo que la solidaridad y la cooperación quedan casi excluidos de cualquier interacción.

Estos criterios han sido también fácilmente difundidos gracias al proceso de globalización que durante el siglo $X X$ ha implicado, entre otras cosas, una serie de transformaciones con respecto a la circulación de información y a su velocidad gracias a innovaciones en los medios de comunicación, las redes de interconexión y los intercambios culturales. La globalización facilita la producción de estilos de vida que son presentados como modelos a seguir y con los que diversos individuos pueden llegar a identificarse, o con los que otros pueden desarrollar relaciones de antagonismo: directivos de compañías transnacionales, multimillonarios, oligarcas, estrellas y celebridades ${ }^{20}$.

Estos estilos de vida pueden presentarse como modelos a seguir en la medida en que aparecen siempre como casos de individuos exitosos, que lograron construir sus fortunas y alcanzar niveles de vida muy altos gracias a su emprendimiento y a su esfuerzo personal ${ }^{21}$. No solamente se dicta qué estilo de vida es deseable sino también cuál es el del camino más apropiado para alcanzar el éxito, caracterizado por la lucha individual, la competencia y los análisis permanentes de costo-beneficio. Los medios de comunicación han jugado un papel

\footnotetext{
17 GILL, Stephen, Power and Resistance..., op.cit., p. 139.

18 MACDONALD, Laura, \& RUCKERT, Arne, "Post-neoliberalism in the Americas: an Introduction" en MACDONALD, Laura, \& RUCKERT, Arne (eds.), Post-neoliberalism in the Americas, Palgrave MacMillan, Londres, 2009, pp. $1-18$.

19 BROWN, Wendy, "Neoliberalism and..., op.cit.

${ }^{20}$ BAYART, Jean-François, Global Subjects. A Political Critique of Globalization, Polity Press, Cambridge, 2007.

${ }^{21}$ Ibídem.
} 
fundamental en la construcción y difusión de este tipo de imágenes que, en últimas, terminan por propiciar y legitimar la racionalidad neoliberal.

La solidaridad, el trabajo colectivo y los beneficios diferentes a las ganancias materiales quedan excluidos de la trayectoria de los emprendedores exitosos, lo que sumado a los esfuerzos institucionales por reducir agrupaciones con carácter no empresarial, han terminado por amenazar las formas de organización social orientadas a defender intereses colectivos. En América Latina, por ejemplo, el disciplinamiento de mercado ha producido tres patrones de dislocación social: privaciones materiales e inseguridades, amenazas a la identidad cultural y retos a las comunidades y a la noción de autonomía ${ }^{22}$, que dificultarían la coordinación de acciones en la defensa y la persecución de objetivos colectivos.

Los modelos keynesiano y del Estado desarrollista permitieron que se organizaran y se fortalecieran movimientos obreros y movimientos campesinos - fundamentalmente en América Latina-, pero éstos fueron golpeados por las reformas neoliberales y sus impactos. De igual forma, los partidos de masas se profesionalizaron gracias al impacto de los medios de comunicación y las nuevas formas de adelantar campañas políticas ${ }^{23}$, lo que produjo una fragmentación de la sociedad civil y una especie de desinstitucionalización de la representación política ${ }^{24}$.

A pesar de ello la globalización neoliberal y las transformaciones que ésta ha implicado, ofrecen también oportunidades para la recuperación de formas de organización social solidarias y para el fortalecimiento de aquellas que no sucumbieron ante políticas neoliberales como la legislación antisindical. Las innovaciones tecnológicas como internet y sus redes sociales, los medios de comunicación y los flujos migratorios han ofrecido posibilidades para la organización de movimientos sociales y colectivos de otra naturaleza ${ }^{25}$ con el propósito de denunciar los excesos del neoliberalismo no sólo en materia económica, sino también política, social, ética y medio ambiental.

Hay mayor disponibilidad de información sobre las problemáticas y los acontecimientos en las más diversas regiones del mundo, lo que facilita el acercamiento, el conocimiento y el posicionamiento frente a diversas problemáticas globales, nacionales y locales. De igual forma, sectores sociales movilizados en el Tercer Mundo han encontrado en estas herramientas una forma de buscar aliados internacionales importantes -ONG, movimientos sociales de largas trayectorias, representantes políticos, académicos influyentes, etc. ${ }^{26}$ - que los han ayudado a adelantar sus luchas políticas y se han solidarizado con ellos a partir de la identificación de problemas similares o de los efectos globales de problemas localizados.

\footnotetext{
22 ROBERTS, Kenneth. "Beyond Neoliberalism: Popular Responses to Social Change in Latin America" en BURDICK, John, OXHORM, Philip \& ROBERTS, Kenneth (eds.), Beyond Latin America, Societies and Politics at the Crossroads, Palgrave MacMillan, Londres, 2009, pp. 1-13.

23 PANEBIANCO, Angelo, Modelos de Partido, Alianza editorial, Madrid, 1982.

${ }^{24}$ ROBERTS, Kenneth. "Beyond Neoliberalism..., op.cit.

${ }^{25}$ FLORINI, Ann, "Who Does What? Collective Action and the Changing Nature of Authority" en BIELER, Andreas, HIGGOTT, Richard \& UNDERHILL, Geoffrey (eds.), Non- State Actors and Authority in the Global System, Routledge, Londres, 2002, pp. 15- 31.

${ }^{26}$ KECK, Margaret \& SIKKINK, Kathryn, Activistas Sin Fronteras, Siglo XXI editores, México, 2000.
} 
Los efectos negativos del neoliberalismo en términos de las condiciones materiales de vida también han sido transformados en oportunidades, por parte de las organizaciones sociales, para la recuperación y la construcción de solidaridad social. Tal es el caso tanto de los movimientos organizados a partir de consecuencias nefastas como el desempleo o la mercantilización de las tierras agrarias comunitarias, como de los movimientos con reivindicaciones anteriores a la era neoliberal que logran expandir su base de militantes o de simpatizantes a partir de la profundización de sus problemas como resultado de la implementación de políticas neoliberales.

\section{Resistencias contra el neoliberalismo: algunos conceptos útiles}

A partir de esta descripción del neoliberalismo y de los espacios son aprovechados por las resistencias que se organizan en su contra se hace una propuesta analítica que permite conocer los elementos que facilitan su organización, sus procesos de interacción y el alcance de las propuestas alternativas que construyen. Se toma entonces como punto de partida un marco teórico neogramsciano ${ }^{27}$ que ayuda a superar la separación artificial entre lo local y lo global, o lo nacional y lo internacional, debido a que toma en consideración las interacciones permanentes entre fuerzas productivas, formas de estado y órdenes mundiales, esferas en las que es posible encontrar configuraciones particulares de ideas, capacidades materiales e instituciones ${ }^{28}$. En ese mismo sentido, reconoce el rol y la importancia de actores no estatales en la política internacional, dado que las definiciones de estado y sociedad civil que se plantean no se asumen como rasgos o características dadas sino como construcciones sociales en las que hay relaciones y tensiones de poder todo el tiempo.

Esta perspectiva asume la importancia equivalente de las condiciones materiales y las ideas en la configuración de órdenes hegemónicos y de alternativas contrahegemónicas. Así, hay también un reconocimiento de relaciones de poder y disputas alrededor de la construcción del orden social, reforzando uno de los argumentos centrales de los que parte este trabajo: la globalización neoliberal genera al mismo tiempo las condiciones para la expansión de mercado, así como para las organizaciones de las resistencias en su contra ${ }^{29}$, así sea únicamente en el espacio de la imaginación ${ }^{30}$.

Este último espacio es muy relevante para la organización de resistencias locales articuladas globalmente, en la medida en que es donde se encuentran las ideas, personas, ideologías e imágenes que circulan mediante flujos en relaciones de disyunción ${ }^{31}$ que se construya el vínculo global-local. Este reconocimiento, a su vez, permite dar cuenta de que la resistencia global contra el neoliberalismo se entiende mejor como respuestas locales al desarrollo desigual de este último ${ }^{32}$, que coinciden a partir del encuentro horizontal de unos

\footnotetext{
${ }^{27}$ COX, Robert, "Social Forces, States and World Orders Beyond International Relations Theory" en MillenniumJournal of International Relations, Vol. 10, n 2, 1981, pp. 126-155. GILL, Stephen, Power and Resistance in the New World Order, Palgrave McMillan, Nueva York, 2008.

${ }^{28}$ COX, Robert, "Social Forces, States..., op.cit.

29 GILLS, Barry, "Introduction: Globalization..., op.cit.

${ }^{30}$ APPADURAI, Arjun, Modernity at Large. Cultural Dimensions of Globalization, Minnesota University Press, Minneapolis, 1996, 178-199. APPADURAI, Arjun, "Grassroots Globalization and Research Imagination", en APPADURAI, Arjun (ed.) Globalization, Duke University Press, Durham, 2001, pp. 1-21.

${ }^{31}$ APPADURAI, Arjun, "Grassroots Globalization and..., op.cit.

32 MORTON, Adam David, Unravelling Gramsci: Hegemony and Passive Revolution in the Global Economy, Pluto
} 
discursos y prácticas que se perciben como globales y locales al mismo tiempo.

Este encuentro se da efectivamente través de los mecanismos de localización/ vernaculización ${ }^{33}$ y enmarcamiento global ${ }^{34}$ que son facilitados, a su vez, por características estructurales del sistema global, a saber: primero, violencia estructural del neoliberalismo, que es percibida y experimentada en la forma de amenazas palpables y sufrimiento en la vida cotidiana de las personas, por lo que contribuye al desarrollo de empatía y solidaridad entre distintos grupos sociales ${ }^{35}$; segundo, expresiones del movimiento alterglobalización, entendidas como aquellos elementos concretos que permiten ver en la práctica el proceso de este movimiento y que se describen con mayor detalle en la siguiente sección; tercero, herramientas tecnológicas como internet, viajes aéreos, medios masivos de comunicación y facilidad en los intercambios que son aprovechados por los activistas sociales en todo el mundo; y, cuarto, flujos en relaciones de disyunción, entendidos como la forma en que la información que se transmite va en un sentido distinto al de la realidad cotidiana de muchas personas. Son la vía por la que lo local y lo global se conectan, de manera diferenciada, pero articulada y permiten ver que "la globalización produce problemas que se manifiestan en formas intensamente locales" ${ }^{\prime 36}$ a pesar de estar profundamente anclados en dinámicas globales.

Los movimientos y organizaciones sociales se encuentran en un proceso constante de apropiación y resignificación de discursos, símbolos, estrategias, conflictos y antagonistas en su ejercicio de la resistencia contra el neoliberalismo. Este proceso puede definirse mejor como como un encuentro permanente dentro del sistema global ${ }^{37}$, en el que tiene lugar una articulación de prácticas y dinámicas locales y globales. Lo global y lo local se encuentran en una relación horizontal de apropiación y resignificación facilitada por las características estructurales del sistema global.

Estos encuentros tienen lugar a través de dos mecanismos que permiten que los conflictos, los discursos y las prácticas de las resistencias contra el neoliberalismo viajen desde lo global hasta lo local y viceversa: el enmarcamiento global de las luchas y proyectos locales, y la localización/vernaculización de las luchas y proyectos globales. Una vez las prácticas y dinámicas locales y globales se encuentran en un marco de horizontalidad, tiene lugar una construcción y reconstrucción de alianzas, estrategias, símbolos, blancos, imaginarios y solidaridad, que dotan de sentido ese proceso de cambio social que es el movimiento alterglobalización tanto en lo local como lo global. Éstos son el producto de la articulación local-global, por lo que no es posible comprender el ejercicio de la resistencia contra el neoliberalismo y los proyectos alternativos que se enmarcan dentro del movimiento alterglobalización si se analiza como un simple cambio de escala y se privilegia una de ellas

Press, Londres, 2007, pp. 178-199.

${ }^{33}$ ESCOBAR, Arturo, Una Minga para el Postdesarrollo: Lugar, Medio Ambiente y Movimientos Sociales en las Transformaciones Globales, Ediciones Desde Abajo, Bogotá, 2012. APPADURAI, Arjun, Modernity at Large... op.cit.

34 TARROW, Sidney, The New Transnational Activism... op.cit

35 REITAN, Ruth, Global Activism, Routledge, Nueva York, 2007.

${ }^{36}$ APPADURAI, Arjun, "Grassroots Globalization and..." op.cit.

${ }^{37}$ SKLAIR, Leslie, Sociología del Sistema Global, Gedisa, Barcelona, 2003. 
en su análisis, tal y como se puede observar en la siguiente figura:

Figura 1. Encuentros entre lo local y lo global en la resistencia contra el neoliberalismo.

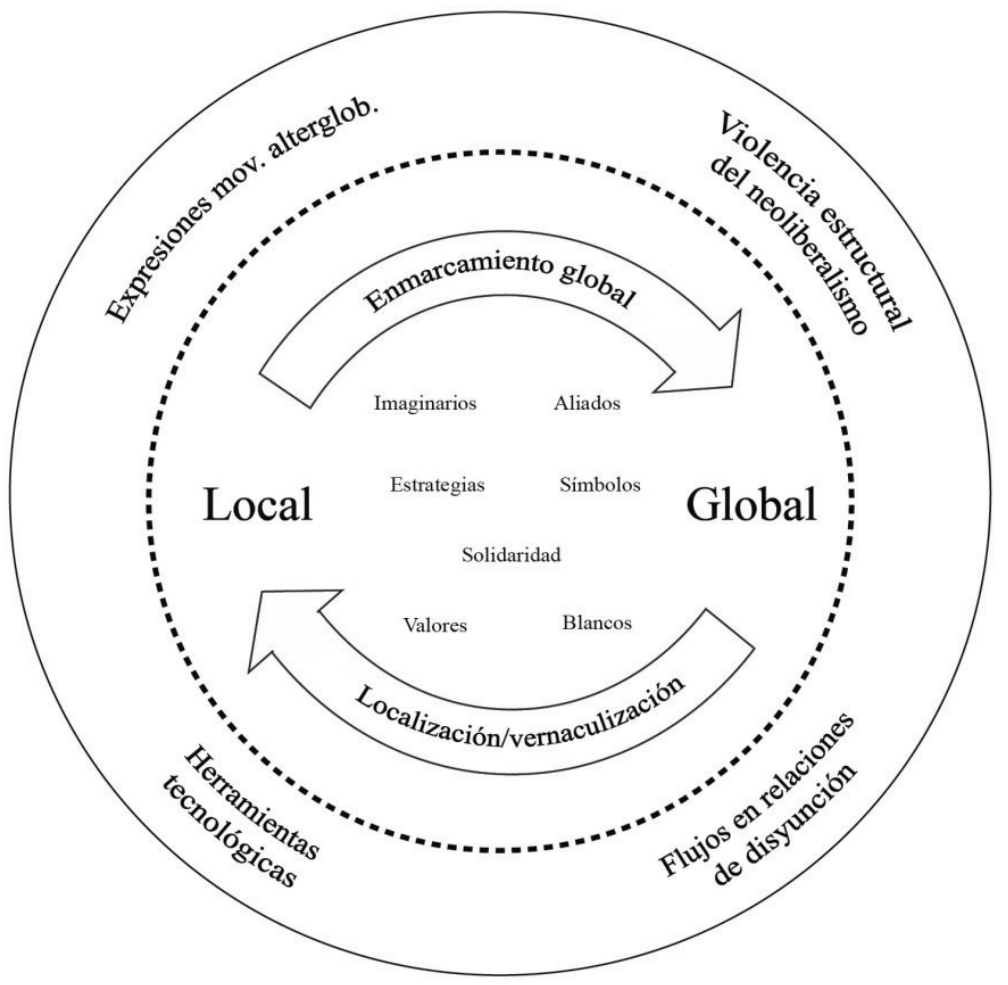

Fuente: elaboración propia.

En ese sentido, la resistencia contra el neoliberalismo no puede entenderse como algo puramente global o local, sino más bien como una práctica política contestaría contenida en ese encuentro permanente, donde diferentes formas de resistencia se interrelacionan y se transforman a partir de elementos estructurales y de las acciones concretas de los mismos movimientos, organizaciones y activistas sociales. Esto se ilustra mucho mejor a través del análisis del movimiento alterglobalización de la próxima sección.

\section{Movimiento alterglobalización}

Muchas de las formas de resistir al neoliberalismo han convergido en el denominado movimiento alterglobalización, cuyo periodo de auge puede enmarcarse entre 1999 y 2005. Al indagar por sus orígenes, se pueden identificar varios hitos: la creación de la Vía Campesina en Bangalore en 1993, ${ }^{38}$ el levantamiento del Ejército Zapatista de Liberación Nacional-EZLN ${ }^{39}$ en Chiapas

${ }^{38}$ La Vía Campesina se creó formalmente en 1993 como una reacción contra el control creciente de la OMC sobre las políticas agrícolas y alimentarias: "las políticas agrícolas y los agronegocios se estaban tornado cada vez más globalizados, por lo que los pequeños campesinos necesitaban desarrollar y luchar por una visión común" (ver: www.laviacampesina.org)

${ }^{39}$ Este levantamiento fue una acción del Ejército Zapatista de Liberación Nacional-El EZLN, un movimiento indígena mexicano cuyas reivindicaciones centrales se encuentran en la posesión de la tierra y en la inclusión de los indígenas mexicanos en el proceso modernizador mexicano sin anular o borrar sus identidades étnicas. Su lucha contra el neoliberalismo se fundamenta en que el Estado mexicano inició una contrarreforma agraria en la década de los 90 para cumplir con las condiciones necesarias para firmar el Tratado de Libre Comercio con Estados Unidos y Canadá. 
en 1994, las protestas contra el Grupo de los 8-G-8 y el lanzamiento de la primera campaña global de la red Reclaim the Streets ${ }^{40}$ en Birminghan en 1998; la creación de ATTAC ${ }^{41}$ en París en 1998; la batalla de Seattle en 1999; y el I Foro Social Mundial-FSM en Porto Alegre en $2001^{42}$.

En este proceso el EZLN ha sido un actor fundamental. Desde su levantamiento en 1994, ha logrado tender un puente entre lo local y lo global ${ }^{43}$ gracias a su comprensión de la globalización neoliberal y la forma como la resistencia en su contra debe desarrollarse; en otras palabras, el EZLN entiende el neoliberalismo como una forma de racionalidad política que está presente y tiene manifestaciones en diferentes niveles de la vida social - desde lo global hasta la vida cotidiana-, evidenciando la necesidad de que las resistencias tengan lugar de la misma forma y se articulen entre sí. Así, la forma de resistir mostrada por el EZLN implica la coordinación con grupos sociales en México y con redes transnacionales de resistencia ${ }^{44}$.

Este puente se materializa en acciones como la organización del I Encuentro por la Humanidad y Contra el Neoliberalismo en Chiapas en 1996, mejor conocido como I Encuentro Intergaláctico. Este tuvo lugar del 27 de julio al 3 de agosto de 1996 en comunidades autónomas zapatistas, donde se ubicaron las mesas de trabajo de política, economía, cultura, sociedad y culturas indígenas, respectivamente ${ }^{45}$. Allí participaron cerca de 5000 activistas de 42 países diferentes con el objetivo de retar al neoliberalismo, como se hace evidente en un fragmento del discurso inaugural del Comité Clandestino Revolucionario del EZLN:

"Hoy, miles de corazones de los cinco continentes se viven aquí, en las montañas del sureste mexicano, por la humanidad y contra el neoliberalismo. Hoy, miles de seres humanos de los cinco continentes gritan su "iya basta!" aquí, en las montañas del sureste mexicano. Gritan iya basta! al conformismo, al nada hacer, al cinismo, al egoísmo hecho dios moderno. Hoy, miles de pequeños mundos de los cinco continentes ensayan un principio aquí, en las montañas del sureste mexicano. El principio de la construcción de un mundo nuevo y bueno, es decir, un mundo donde quepan todos los mundos"46.

${ }^{40}$ Reclaim the Streets empezó en Londres en 1995 como una iniciativa para reivindicar las calles de la ciudad en tanto bien común a través de fiestas callejeras (street parties): una combinación de protestas y elementos festivos y carnavalescos. La iniciativa se extendió primero por otras ciudades inglesas y luego a diferentes ciudades del mundo. En 1998 tuvo lugar la primera fiesta callejera global ( $g$ lobal street party) en el marco de una reunión del G-8 en Birmingham, Inglaterra, coordinándose acciones simultáneas en ciudades como Londres, Melbourne, Buenos Aires, Bogotá, Tokio y Seattle, entre otras.

${ }^{41}$ Asociación por la Gravación de las Transacciones Financieras para la Ayuda de los Ciudadanos- ATTAC. Esta asociación francesa apunta a gravar las transacciones financieras de las grandes compañías con el $1 \%$ de sus ganancias anuales, con el fin de subsanar la deuda externa de los países más pobres y mejorar las condiciones de vida de los ciudadanos excluidos.

42 PLEYERS, Geoffrey, Alter-Globalization. Becoming Actors in the Global Age, Polity Press, Cambridge, 2010.

${ }^{43}$ WORTH, Owen, Resistance in the Age of Austeriry, Zeld, Londres, 2013, pp. 9-71.

${ }^{44}$ RUPERT, Mark, "In the Belly of the Beast: Resisnting Globalisation and War in a Neo-Imperial Moment" en ESCHLE, Catherine \& MAIGUASHCA, Bice (eds.), Critical Theories, International Relations and 'the Anti-Globalisation Movement'. The Politics of Resistance, Routdledge, Nueva York, 2005, pp. 36-52.

45 MUÑOZ, Gloria, EZLN: 20 Y 10, El Fuego y La Palabra, La Jornada, México, 2003.

${ }^{46}$ EZLN (Ejército Zapatista de Liberación Nacional), Palabras de la Comandancia General del EZLN en el Acto de Inicio del Primer Encuentro Interncontinental por la Humanidad y contra el Neoliberalismo, Chiapas, 1996: http://enlacezapatista.ezln.org.mx/1996/07/27/ccri-cg-inicio-del-primer-encuentro-intercontinental-por-lahumanidad-y-contra-el-neoliberalismo/ [Consultado el 12 de octubre de 2018] 
Uno de los resultados inmediatos de este encuentro fue la organización de la red Acción Global de los Pueblos ${ }^{47}$, desde donde se sentaron las primeras bases para el proceso del movimiento alterglobalización ${ }^{48}$. Otros procesos de resistencia tuvieron lugar de manera simultánea, como las campañas contra del Acuerdo Multilateral de Inversiones impulsadas dentro del marco de una red de activistas sociales, intelectuales, ONG y movimientos sociales que se oponía a los efectos negativos de la liberalización económica, y que sirvieron para frenar las negociaciones de este hasta $1998^{49}$. Como resultado de esta campaña y de otros factores como la crisis financiera de Asia en 1997-1998, las huelgas en Francia en 1995 y $1998^{50}$ y la existencia de un medio de información alternativo como el periódico Le Monde Diplomatique, en 1998 se creó ATTAC. También se llevaron a cabo campañas por la condonación de la deuda externa de los países del Tercer Mundo promovidas por la organización cristiana Jubileo $2000^{51}$. Estas campañas estuvieron acompañadas por grandes protestas en contra de bloques de Estados poderosos y las instituciones de Bretton Woods durante 1998, como las que tuvieron lugar en Birmingham, Reino Unido, y Ginebra, Suiza, contra el G-8 y la OMC respectivamente.

Pese a ello, la atención mediática hacia el movimiento no llegó sino hasta diciembre de 1999 cuando aconteció una protesta en contra de la III cumbre ministerial de la OMC en Seattle, cuyo resultado inmediato fue su suspensión. A partir de este momento, conocido como la Batalla de Seattle, se hizo evidente la existencia de una nueva dinámica en el panorama internacional ${ }^{52}$, que sería conocida como movimiento alterglobalización, cuya característica más novedosa era la convergencia de diferentes activistas opuestos a la globalización neoliberal para manifestar su descontento y señalar sus efectos negativos ${ }^{53}$.

Pleyer $^{54}$ identifica tres etapas en el movimiento. En la primera, diferentes movimientos y organizaciones convergieron en megaprotestas, reuniones de expertos y coaliciones desde donde era posible retar colectivamente la ideología dominante. En ello, el uso de herramientas tecnológicas fue de crucial importancia, ya que estas permitieron el intercambio de información y experiencias, en un proceso fundamentado por la solidaridad derivada de la experimentación de la violencia estructural del neoliberalismo. Los intelectuales y las organizaciones más grandes como ATTAC y Focus on the Global South ${ }^{55}$ fueron muy importantes en esta fase,

47 PLEYERS, Geoffrey, Alter-Globalization. Becoming... op.cit. SEOANE, José \& TADDEI, Emilio, "De Seattle a Porto Alegre. Pasado, Presente y Futuro del Movimiento Anti-Mundialización Neoliberal" en SEOANE, José \& TADDEI, Emilio (eds.), Resistencias Mundiales de Seattle a Porto Alegre CLACSO, Buenos Aires, 2001, pp. 105- 129.

${ }^{48}$ SEOANE, José \& TADDEI, Emilio, "De Seattle a Porto Alegre..., op.cit

${ }^{49}$ Ibídem.

50 STEGER, Manfred, GOODMAN, James, \& WILSON, Erin, Justice Globalism: Ideology, Crisis, Policy, Sage, Londres, 2013.

${ }^{51}$ DELLA PORTA, Donatella, "The Social Bases of the Global Justice Movement. Some Theoretical Reflections and Empirical Evidence from The First European Social Forum", Working Paper, 2005, www.unrisd.org, consultado en 2008.

52 SMITH, Jackie, "Democratizing Globalization? Impacts and Limitants of Transnational Social Movements" en American Sociological Association Annual Meeting, 2004: http://d-scholarship.pitt.edu/20771/ [Consultado el 16 de octubre de 2018]

${ }^{53}$ KLEIN, Naomi, Vallas y Ventanas, Paidós, Barcelona, 2002.

${ }^{54}$ PLEYERS, Geoffrey, Alter-Globalization... op.cit.

${ }^{55}$ Focus on the Global South es una organización no gubernamental fundada en 1995 en Bangkok, Tailandia, con el ánimo de, cuestionar y retar la globalización neoliberal, el militarismo y el poder creciente de las compañías transnacionales, y construir alternativas desde y con el sur global. Sus actividades se concentran en 
ya que lograron atraer la atención del público al tema de la globalización y la necesidad de cuestionar el neoliberalismo, abriendo la posibilidad de plantear un debate público global alrededor de esto, que incluía la identificación de valores y enemigos comunes.

La segunda etapa tuvo lugar en el periodo 2001-2005, durante el inicio y la expansión del Foro Social Mundial. Éste se organizó desde las redes establecidas en las campañas y megaprotestas de la fase anterior, retomando las conclusiones del Encuentro Intergaláctico y como resultado de la iniciativa de actores como ATTAC y el Movimiento de los Trabajadores Rurales Sin Tierra -MST. ${ }^{56}$ A partir de 2005 el movimiento alterglobalización llegó a su tercer momento, en el que algunos de los movimientos, organizaciones y redes más importantes, como ATTAC, alcanzaron un cierto grado de estancamiento, tensiones y rupturas, que tuvieron como resultado un periodo de eventos menos exitosos. Sin embargo, durante esta misma etapa se produjo una expansión o ampliación del movimiento alterglobalización en la medida en que experiencias de resistencia contra el neoliberalismo originadas en diferentes regiones del mundo y a diferentes escalas empezaron a vincular sus prácticas y sus discursos con los del proceso más amplio, sin que éstos necesariamente tomaran parte en expresiones concretas como las megaprotestas o el FSM.

Por otra parte, es importante subrayar que algunos cambios en el panorama político mundial incidieron en las transformaciones del movimiento. La crisis financiera de 2008, por ejemplo, contribuyó a que muchos movimientos se enfocaran nuevamente en sus contextos locales inmediatos de desempleo, empobrecimiento y políticas públicas de austeridad. Esto no quiere decir que la resistencia global contra el neoliberalismo se haya terminado o que esté en un momento de estancamiento. Al contrario, este artículo argumenta que el movimiento alterglobalización está en una transformación que se hace evidente al contemplar movilizaciones más recientes como Occupy Wall Street ${ }^{57}$ y protestas como las de los Indignados, ${ }^{58}$ así como experiencias de resistencia y lucha anteriores a este periodo que privilegian sus estrategias y acciones locales, en la construcción de alternativas, como las fábricas recuperadas en Argentina y los comités de agua en Bolivia.

\footnotetext{
la investigación, el trabajo con movimientos de base, la construcción de redes de activistas, las campañas de defensa transnacional y el activismo político. Ver: http://focusweb.org/content/who-we-are.

${ }^{56}$ EI MST es un movimiento social brasilero conformado por trabajadores rurales (campesinos, agrónomos, veterinarios, ingenieros y profesores, entre otros), que exigen una reforma agraria y una mayor presencia del Estado en términos de salud, educación, protección de los derechos humanos y generación de empleo. De igual forma han incorporado demandas alrededor del tema de la soberanía alimentaria en los últimos años debido, en gran parte, al auge de los agronegocios en Brasil.

${ }^{57}$ El movimiento Occupy es el nombre con el que se designan las diferentes movilizaciones que han tenido lugar alrededor del mundo desde 2011, cuando estalló la crisis financiera. La primera de éstas se vio en Estados Unidos con la iniciativa de Occupy Wall Street en la ciudad de Nueva York, expandiéndose rápidamente por otras ciudades del país, y desde entonces se ha replicado en diferentes lugares del mundo. Sus objetivos no se reducen a la denuncia y la confrontación de los actores políticos y económicos responsables por la crisis actual, sino que se compaginan con la búsqueda de alternativas del movimiento alterglobalización para lo cual desarrollan actividades orientadas a la construcción de fuertes vínculos de solidaridad, intercambio de opiniones y experiencias y difusión de información.

${ }^{58}$ Este es el nombre con el que la prensa empezó a designar a los manifestantes que han tomado parte en las distintas concentraciones y movilizaciones masivas que tuvieron lugar en España a lo largo de 2011 y 2012 replicadas con menor fuerza en los últimos años). Estas manifestaciones expresan el descontento generalizado por los altos niveles de desempleo, el aumento en los costos de las hipotecas y las leyes restrictivas de libertades. La primera gran manifestación tuvo lugar el 15 de mayo, organizada a partir de la iniciativa de colectivos como Democracia Real Ya!, V de vivienda e Hipotecados, y logró reunir una amplia variedad de activistas y ciudadanos comunes y corrientes indignados por la situación de precariedad social.
} 
Esa transición hace aún más evidente el vínculo entre lo local y lo global, resaltando la necesidad de tender puentes entre diferentes áreas de las ciencias sociales ya planteada en trabajos de relaciones internacionales ${ }^{59}$ y movimientos sociales ${ }^{60}$ al tiempo que muestra las limitaciones de privilegiar la dimensión global en el análisis y la aproximación al movimiento como un actor o coalición de actores unificados. El hecho de que varias organizaciones estén privilegiando su trabajo local pone en evidencia la importancia de esta dimensión en la producción y el ejercicio de resistencia contra el neoliberalismo, sin que ello implique una negación o desconocimiento de la dimensión global.

El cambio social no puede entenderse como una transformación a tener lugar en el plano global o desde las organizaciones internacionales, sino como esa determinación colectiva de plantear alternativas a la realidad capitalista a través de prácticas concretas por parte de los actores involucrados ${ }^{61}$, que pueden materializarse efectivamente en sus contextos inmediatos o aparecer como metas en el horizonte que guían sus acciones. Esta forma de entender el cambio social ofrece una ventaja política y una teórica frene a una perspectiva más "globalizante" e inmediatista: permite visibilizar la pluralidad de alternativas que se han llevado a la práctica y contribuye a la discusión teórica sobre los órdenes sociales posibles por fuera del marco dominante de la economía de mercado y la democracia representativa.

Así las cosas, se propone definir al movimiento alterglobalización como proceso de cambio social en el que convergen movimientos, organizaciones y activistas sociales distintos y diferenciables que se oponen al proceso de globalización neoliberal, y desde el cual buscan formular y construir alternativas al orden actual. Este proceso se caracteriza por la diversidad de actores, prácticas y propuestas, que lejos de ser una limitación, es una gran fortaleza que lo apuntala. Este proceso tiene algunas manifestaciones en el plano global que, sin embargo, tienen profundos arraigos y significados en los procesos locales.

Pese a esa diversidad, los movimientos, organizaciones y los activistas que hacen parte del movimiento alterglobalización comparten algunos valores, reivindicaciones, demandas y prácticas, siendo la oposición a la globalización neoliberal su punto de convergencia más significativo. Esta oposición se ejerce en diferentes formas, dependiendo del impacto de las políticas neoliberales en la vida de las distintas comunidades, pero siempre organizada alrededor de unos consensos mínimos: el carácter global y negativo de tales políticas; los blancos comunes en agentes del neoliberalismo encarnados en compañías transnacionales, las organizaciones económicas internacionales y los Estados poderosos; la importancia del trabajo colectivo en la resistencia; y la necesidad de luchar en diferentes espacios de la vida social y en diferentes escalas territoriales.

Estos consensos mínimos pueden incluso ir más allá y dar cuenta de una visión de

59 SIKKINK, Kathryn, "Patterns of Dynamic Multilevel Governance and the Insider-Outsider Coalition" en DELLA PORTA, Donatella \& TARROW, Sidney (eds.), Transnational Protest and Global Activism, Rowman and Littlefield publishers, Nueva York, 2005, pp. 151-173.

60 TARROW, Sidney \& DELLA PORTA, Donatella, "Conclusion: "Globalization", Complex Internacionalism and Transnational Contention" en TARROW, Sidney \& DELLA PORTA, Donatella (eds.), Transnational Protest and Global Activism, Rowman and Lttilefiel publishers, Nueva York, 2005, pp. 227-246.

${ }^{61}$ DINERSTEIN, Ana, Movimientos Sociales y Autonomía Colectiva. La Polítia de la Esperanza en América Latina, Capital Intelectual, Buenos Aires, 2013, pp. 21-38. 
mundo compartida, que Steger y Wilson ${ }^{62}$ definen como globalismo de justicia, basado en el compromiso con la justicia social y en el reconocimiento de la interconexión entre los varios niveles de la vida política que se han producido en el mundo de la globalización ${ }^{63}$. Este se construye sobre la base de siguientes conceptos fundamentales como: transformación o cambio de paradigma político y económico, entendiendo el cambio como positivo y necesario para evitar el desastre; democracia participativa, como fuente de legitimidad tanto para las organizaciones del movimiento, como para los gobiernos y los regímenes internacionales; igualdad de acceso a recursos y oportunidades para todos, como una forma para promover la inclusión de sectores tradicionalmente marginados; justicia social, concebida en términos de equidad, democracia, diversidad, sostenibilidad y derecho a la información; derechos universales; solidaridad global, asociada con temas como cooperación, unidad y acción conjunta con aquellos con metas y aspiraciones afines; y, sostenibilidad socioeconómica y ambiental, entendida como la preservación del medio ambiente y de recursos como empleo, comida, producción y desarrollo ${ }^{64}$.

Estos conceptos están presentes dentro de las reivindicaciones, demandas, estrategias y prácticas cotidianas de los movimientos y organizaciones que hacen parte del movimiento alterglobalización. En el caso del EZLN, por ejemplo, la democracia y la justicia son reivindicaciones centrales, al tiempo que demandan derechos universales y medidas redistributivas ligadas a la noción de sostenibilidad socioeconómica. El MST, por su parte, enmarca su lucha por la tierra dentro de nociones como la equidad, justicia social y derechos universales, conectando todo con la necesidad de mecanismos de sostenibilidad ambiental. La justicia social y ambiental, los derechos universales y la defensa de los bienes comunes, por su parte, también aparecen como las reivindicaciones centrales de la asociación italiana Ya Basta!, ${ }^{65}$ que ha construido su organización sobre la base de la solidaridad social con movimientos locales, nacionales e internacionales.

Ahora, con el fin de dar cuenta de la dimensión global del movimiento alterglobalización es necesario retomar algunas acciones y elementos concretos que expresan la existencia de un proceso de articulación y convergencia de actores afines con el globalismo de justicia, al tiempo que lo facilitan: protestas, coaliciones y foros sociales.

\subsection{Protestas}

Las protestas constituyen una de las expresiones más fuertes y más populares del movimiento alterglobalización. Pueden entenderse como una forma de acción coordinada entre diferentes movimientos y organizaciones sociales embarcadas en luchas y resistencias

62 STEGER, Manfred, \& WILSON, Erin, "Anti-Globalization or Alter-Globalization? Mapping the Political Ideology of the Global Justice Movement" en International Studies Quarterly, Vol. 56, no 3, 2012, pp. 439-454.

${ }^{63}$ Ibídem.

${ }^{64}$ Ibídem.

65 Ya Basta! es un movimiento italiano que se organizó a partir de la experiencia del levantamiento zapatista de 1994 y del I Encuentro Intergaláctico en 1996. El objetivo de este movimiento es ir más allá de la expresión constante de solidaridad con las comunidades zapatistas y construir instrumentos de acción política en Italia que abarcaran también otros procesos de movilización en el mundo como aquellos en el territorio palestino y, fundamentalmente, en América Latina. Sus acciones tienen como base, lo que ellos denominan como la "diplomacia desde abajo" y el turismo solidario, que apuntan a conocer otras experiencias de lucha y forjar vínculos que permitan articular las distintas iniciativas de autogestión en el mundo. Ver: http://www.yabasta. it/ 
contra la implementación de políticas neoliberales alrededor del mundo66. Estas acciones son facilitadas por la difusión y el intercambio de información entre distintos actores sociales, así como por la construcción de una solidaridad compartida alrededor de la resistencia contra el neoliberalismo.

La batalla de Seattle en 1999 abrió el ciclo de protestas conocidas como megaprotestas, con acciones impactantes hasta 2001 en ciudades como Washington (2000), Praga (2000), Melbourne (2000) y Génova (2001), debido al número de manifestantes y a la atracción mediática que alcanzaron. Seattle representa el primer momento de encuentro de la diversidad en el proceso de resistencia y denuncia contra el neoliberalismo, que se materializa, en primer lugar, a través de la convergencia de actores distintos como los tute bianche, ${ }^{67}$ el bloque negro, ${ }^{68}$ sindicatos de trabajadores, movimientos ambientalistas, ONG de derechos humanos y sindicatos agrícolas, entre otros ${ }^{69}$.

El ciclo se cerró con la megaprotesta que tuvo lugar en Génova en contra de la Cumbre del G-8 celebrada entre el 19 y el 22 de julio de 2001 . Al igual que en las demás, convergieron diferentes actores y diversas estrategias de movilización, por lo que se vieron acciones tan variadas como marchas pacíficas, acciones de destrucción de bienes en las vías públicas y expresiones artísticas. Sin embargo, su particularidad radicó en que fue el primer escenario donde los agentes policiales desplegaron toda la fuerza represiva y punitiva contra los manifestantes alterglobalización, al punto de causar la muerte del joven militante Carlo Giuliani, dejar varios heridos y al menos 25 detenidos, todos hechos denunciados por Amnistía Internacional.

Si bien las megaprotestas fueron facilitadas por las plataformas de intercambio de información y redes sociales en internet, también lograron constituir un espacio de reunión y convergencia. Son la evidencia de que existe un proceso de articulación alrededor de "enemigos" y blancos compartidos como la OMC, el FMI, el BM y las compañías transnacionales, que terminan por quedar en el centro del debate político, al tiempo que cuestionan el capitalismo, los resultados de los tratados de libre comercio y el poder que dichos actores tienen en la vida cotidiana de las personas ${ }^{70}$. Esta articulación, aunque temporal, abrió la oportunidad para un intercambio inicial de repertorios, estrategias y discursos que, a su vez, implicó desacuerdos, discusiones y tensiones entre los mismos actores.

\subsection{Redes y Coaliciones Transnacionales}

Tomando como punto de partida las experiencias de resistencia y la intensificación en el

66 TARROW, Sidney, The New Transnational ... op.cit.

67 Los tute bianche son un movimiento italiano de trabajadores desocupados, cuyas estrategias consisten en acudir a prácticas simbólicas tales como el vestir overoles blancos gigantes, trepar edificios, irrumpir en museos o traspasar los cercos policiales con un solo paso. Todo ello con el fin de manifestar su descontento y hacer públicas sus reivindicaciones sobre empleo y condiciones de vida dignas.

${ }^{68}$ El bloque negro es el nombre con el que se han designado los grupos anarquistas que participan en distintas movilizaciones, donde actúan con gran autonomía frente al resto de los activistas, emplean la violencia contra espacios u objetos físicos y se enfrentan con policía.

69 KLEIN, Naomi, Vallas y Ventanas... op.cit.

70 NEGRI, Antonio, Goodbye Mr. Socialism. La Crisis de la Izquierda y los Nuevos Movimientos Revolucionarios, Paidós, Barcelona, 2007, pp. 53-76. 
intercambio de información se han construido redes y coaliciones transnacionales que en algunos casos han facilitado la organización de megaprotestas y que, en otros, se han organizado o fortalecido a partir de ellas. Así, en el primer caso es posible ver redes y coaliciones como 50 Years Is Enough $!^{71}$ y Reclaim the Streets, organizadas en el marco de vinculación de las primeras luchas contra el neoliberalismo de diferentes organizaciones, movimientos y activistas sociales conectados transnacionalmente.

Otro ejemplo importante es La Vía Campesina, que se creó formalmente en 1993 como una reacción contra el control creciente de la OMC sobre las políticas agrícolas y alimentarias: "las políticas agrícolas y los agronegocios se estaban tornado cada vez más globalizados, por lo que los pequeños campesinos necesitaban desarrollar y luchar por una visión común" (La Vía Campesina). Esta visión común parte del planteamiento de alternativas de desarrollo sostenible, concebidas popularmente, donde la preservación y la revalorización de las identidades campesinas y sus estilos de vida son fundamentales en la confrontación con la visión neoliberal72. La vía campesina comprende más de 150 organizaciones locales y nacionales de 70 países diferentes (La Vía Campesina) y sus demandas centrales son la reforma agraria, el trabajo rural dignificado, la sostenibilidad ambiental, la seguridad y soberanía alimentaria, la democratización y los derechos para los trabajadores rurales.

La Vía Campesina ha desarrollado diferentes estrategias de movilización y resistencia que van desde actos simbólicos hasta presencia en organizaciones como la Organización de las Naciones Unidas para la Alimentación y la Agricultura-FAO, reflejando su heterogeneidad, trayectoria y los asuntos que han aparecido desde 1993. Su membrecía también es de carácter diverso en términos de estatus de clase, ideologías y enfoques políticos, por lo que es posible encontrar desde campesinos ricos hasta campesinos sin tierra, lo que genera contradicciones y tensiones internas, aunque reconciliables en la mayoría de los $\operatorname{casos}^{73}$.

Otras coaliciones y redes son mucho más amplias y recogen reivindicaciones de diferentes sectores: campesinos, trabajadores, jóvenes, académicos, desposeídos, ambientalistas, etc. Un ejemplo de ellas en la red Our World Is Not For Sale. ${ }^{74}$ Esta red se organizó como una respuesta a la necesidad de coordinar y vincular todas luchas locales contra el neoliberalismo, identificadas en el marco de las campañas contra el AMI y las protestas de la OMC. Apoya y estimula la colaboración entre organizaciones y movimientos para construir estrategias conjuntas contra la OMC, por lo que sus acciones se concentran fundamentalmente alrededor de reuniones regulares de intercambio y discusión, delegaciones de actores a Ginebra para realizar actividades de lobby frente a la OMC y ofrecer análisis críticos sobre el impacto de

\footnotetext{
7150 years is enough! es una coalición organizada en 1994 con base en Estados Unidos que reúne a cerca de 200 organizaciones diversas (mujeres, ambientalistas, sindicatos, etc.) en este país y alrededor de 185 en 65 países. Su objetivo central es transformar las prácticas y políticas de las instituciones de Bretton Woods y, en función de ello, sus estrategias se concentran en capacitaciones y "entrenamiento" en economía, movilizaciones sociales y defensa de planteamientos políticos antineoliberales. Ver: http://orgs.tigweb.org/50-years-is-enough-network

72 REITAN, Ruth, Global Activism... op-cit.

73 BORRAS, Saturnino, "La Vía Campesina and its Global Campaign for Agrarian Reform" en Journal of Agrarian Change, Vol. 8, no 2-3, 2008, pp. 258-289.

${ }^{74}$ Coalición que agrupa organizaciones, movimientos y activistas sociales independientes que luchan contra el modelo actual de globalización corporativa. 216 organizaciones se articulan alrededor de su compromiso con un sistema de comercio sostenible, socialmente justo, democrático y transparente. Ver: www.ourworldisnotforsale. org
} 
sus políticas, conferencias de prensa, días de acción y manifestaciones para presionar líderes y lograr regulaciones.

Las redes y coaliciones del movimiento siguen siendo reflejo de la diversidad y el dinamismo que hay en este proceso, en la medida en que permiten ver algunos temas puntuales que constituyen preocupaciones centrales para determinadas organizaciones, movimientos y activistas sociales - política agrícola, liberalización comercial, mercantilización de bienes comunes, etc.-, la heterogeneidad y combinación de estrategias -marchas, protestas, campañas, lobby, etc.- y los vínculos complejos de solidaridad que se establecen entre diferentes actores - formar parte de distintas coaliciones-. En ese sentido es válido sugerir que las coaliciones permiten intercambios más amplios que los de solamente información. Éstos se producen también alrededor de la forma como se concibe un problema o un tema puntual desde las perspectivas concretas de las organizaciones y movimientos, y de las estrategias utilizadas para abordarlos y hacerles frente.

A pesar de ello, las redes y coaliciones siguen estando ancladas a temas, regiones o estrategias específicas, que si bien constituyen una de las expresiones del movimiento alterglobalización y tienen mecanismos de articulación más amplios de lo que se pensaría a primera vista, no logran dar cuenta de la "globalidad" o la dimensión global del movimiento por su propia cuenta.

\subsection{Foro Social Mundial}

EI FSM es fruto de otras expresiones del movimiento alterglobalización desde las que se planteó la necesidad de realizar una reunión periódica de organizaciones, movimientos y activistas sociales que permitiera llegar a unos mínimos comunes para formular propuestas alternativas concretas, retomando el compromiso derivado del I Encuentro Intergaláctico. EI FSM se realizó durante sus tres primeras versiones en Porto Alegre y en 2004 se trasladó a Mumbai, India. Desde entonces se ha organizado en diferentes regiones del mundo, con versiones continentales y temáticas, pero manteniendo su centro en Brasil, con lo que se ha propiciado una expansión geográfica que ha servido no sólo para aumentar el número de asistentes, sino también para ampliar la agenda de temas a discutir y la participación de diversos movimientos sociales ${ }^{75}$.

El FSM se concibe como un espacio abierto a organizaciones y movimientos sociales comprometidos con la lucha antineoliberal, con prácticas democráticas y en el que ninguno de ellos podría hacer prevalecer sus objetivos sobre los de otras organizaciones y activistas ${ }^{76}$. En su Carta de Principios se define como:

"Un espacio abierto de encuentro para: intensificar la reflexión, realizar un debate democrático de ideas, elaborar propuestas, establecer un libre intercambio de experiencias y articular acciones eficaces por parte de

75 CEPEDA-MASMELA, Carolina, "¿Dónde Están y Quiénes Son los que Protestan contra la Globalización? Caracterización de las organizaciones participantes en el Foro Social Mundial 2001, 2004 y 2008" en Papel Político, Vol. 21, no 2, 2016, pp. 505-536.

76 TEIVAINEN, Teivo, "Global Democratization without Hierarchy or Leadership? The World Social Forum in the Capitalist World" en GILL, Stephen (ed.), Global Crises and the Crisis of Global Leadership, Cambridge University Pres, Londres, 2012, pp. 181-198. 
las entidades y los movimientos de la sociedad civil que se opongan al neoliberalismo y al dominio del mundo por el capital o por cualquier forma de imperialismo y, también, empeñados en la construcción de una sociedad planetaria orientada hacia una relación fecunda entre los seres humanos y de estos con la Tierra"77.

Siguiendo esta Carta, se encuentra que el FSM se define como un espacio y articulación de movimientos y redes sociales, enfatizando en el carácter civil y no partidista de su composición, con lo cual les otorga un rol central a los movimientos de base. Se caracteriza también por no tener acuerdos fundamentales sobre las alternativas a proponer ni la forma como éstas podrían llevarse a cabo, aunque representa la esperanza de aquello que puede ser pero que aún no llega78. De allí que el FSM se plantee como un espacio horizontal y deliberativo, donde no se deciden planes de acción en su nombre; sin embargo, no todas las organizaciones y movimientos sociales comparten esta posición, y algunas consideran que es necesario adoptar estructuras organizativas que permitan la adopción de mecanismos para asegurar representatividad, responsabilidad y acción.

El FSM entraña una gran diversidad que se refleja también en la coexistencia de distintos enfoques para llevar a cabo la movilización y promover la transformación social. Así, por ejemplo, existe una distinción entre las organizaciones que adoptan prácticas como la prefiguración, creando y viviendo las transformaciones sociales en la vida cotidiana, y las organizaciones que tienen un enfoque más "estratégico" y priorizan las alianzas con otros actores sociales y políticos en aras de alcanzar sus objetivos ${ }^{79}$. De igual forma algunas organizaciones están orientadas a partir de reformas, mientras que otras buscan transformaciones más radicales, cercanas a la noción de revolución ${ }^{80}$.

El Foro también permite intercambios de información, procesos de aprendizaje mutuo y construcción de lazos de solidaridad en un proceso más amplio, sólido y duradero que las megaprotestas y las coaliciones alrededor de temas específicos. De hecho, es posible afirmar que "el FSM ha proporcionado un canal a través del cual muchos de los movimientos de protesta global de los 90 se han convertido en movimientos de democracia global en el siglo $\mathrm{XXI}^{\prime \prime 81}$; esto es, comprometidos con el desarrollo de alternativas en aras de una reconstrucción democrática global.

En ese sentido, el FSM es en una expresión del movimiento alterglobalización que da cuenta de su diversidad ya no sólo en términos ideológicos, de enfoque o reivindicativos, sino también en términos geográficos y de luchas contra el neoliberalismo. Esta ampliación o apertura para los movimientos del Sur tiene tres implicaciones: el primer lugar, les permite compartir sus experiencias de lucha en un espacio global; en segundo lugar, puede crear las bases discursivas para la articulación de esas luchas con el proceso del movimiento

\footnotetext{
77 FSM (Foro Social Mundial), Carta de Principios, Port Alegre, 2001: http://fsmm2018.org/carta-de-principios/ [Consultado el 12 de octubre de 2018]

78 DINERSTEIN, Ana, Movimientos Sociales y Autonomía..., op.cit.

79 TEIVAINEN, Teivo, "Global Democratization without..., op.cit.

80 TORMEY, Simon, Anti-Capitalismo: a Beginner's Guide, Oneworld, Oxford, 2004.

81 TEIVAINEN, Teivo, "Global Democratization without..., op.cit.
} 
alterglobalización; y, finalmente, les ofrece la posibilidad de retroalimentar y, en la medida de lo posible, reconstruir sus luchas particulares a partir de los intercambios, los procesos de aprendizaje y la articulación más amplia con el movimiento alterglobalización ${ }^{82}$.

Entender el movimiento alterglobalización en los términos propuestos permite conocer algunos de los procesos de resistencia que se organizan a nivel local, al igual que las expresiones globales de este proceso. Ello contribuye a mostrar que la resistencia contra la globalización neoliberal se ejerce en ese encuentro permanente entre lo local y lo global, en el que tanto las condiciones materiales, como las ideas, la imaginación y las visiones de mundo son importantes para los intercambios y aprendizajes de los actores sociales.

\section{Conclusiones}

Este artículo proporciona, por un lado, un marco analítico innovador para comprender la relación entre lo local y lo global en el ejercicio de la resistencia contra el neoliberalismo que es útil para entender esta relación y evidenciar que la resistencia no se ejerce de la misma forma en todos los casos y que depende, en gran medida, de la forma como se experimenta la violencia estructural del neoliberalismo. En segundo lugar, la propuesta es útil para visibilizar formas particulares de resistencia contra el neoliberalismo y sus alternativas de cambio social; estas alternativas son distintas y responden a las particularidades del contexto, lo que permite ver el peso que tienen factores estructurales ajenos a la voluntad política de los activistas en la configuración de las mismas.

Esta perspectiva también hace explícita la importancia de los espacios de intercambio e interacción como las coaliciones transnacionales, los foros sociales y las megaprotestas, pero resalta el lugar que tiene la imaginación en el ejercicio de la resistencia local y en su vinculación con expresiones y prácticas de carácter global. Si bien estos espacios de intercambio directo son fundamentales, no podría tener lugar sin la construcción de algo como el globalismo de justicia y la apropiación local de sus conceptos. Ideas y capacidades materiales son centrales en la instauración del neoliberalismo como una forma de racionalidad política pero también lo son en el ejercicio de la resistencia en su contra y en la búsqueda y construcción de alternativas frente a ella.

Finalmente, acercarse a la política internacional desde una perspectiva neogramsciana en relaciones internacionales permite cuestionar el mundo actual y la forma de cómo éste llegó a constituirse ${ }^{83}$. Esto ofrece una gran ventaja para trabajos como este, donde hay una contribución política al visibilizar experiencias contestatarias y alternativas en el debate académico, a partir del que se pueden conocer y comprender sus prácticas de organización, producción y toma de decisión que retan en muchos aspectos la racionalidad liberal y muestran que otro mundo no es sólo posible sino también real.

\section{Bibliografía}

82 CEPEDA-MASMELA, Carolina, "¿Dónde Están y..., op.cit.

${ }^{83}$ COX, Robert, "Social Forces, States and World Orders Beyond International Relations Theory" en MillenniumJournal of International Relations, Vol. 10, n 2, 1981, pp. 126-155. 
APPADURAI, Arjun, Modernity at Large. Cultural Dimensions of Globalization, Minnesota University Press, Minneapolis, 1996, 178-199.

APPADURAI, Arjun, "Grassroots Globalization and Research Imagination", en APPADURAI, Arjun (ed.) Globalization, Duke University Press, Durham, 2001, pp. 1-21.

AUERBACH, Nancy, "The meanings of neoliberalism" en ROY, Raven, DENZAU, Arthur \& WILLET, Thomas (eds.), Neoliberalism. National and Regional Experiments with Global Ideas, Routledge, Nueva York, 2007, pp. 26-50.

BAYART, Jean-François, Global Subjects. A Political Critique of Globalization, Polity Press, Cambridge, 2007.

BORRAS, Saturnino, "La Vía Campesina and its Global Campaign for Agrarian Reform" en Journal of Agrarian Change, Vol. 8, no 2-3, 2008, pp. 258-289.

BROWN, Wendy, "Neoliberalism and the End of Liberal Democracy" en Theory and Event, Vol. 7, no 1, 2003: https://muse-jhu-edu.ezproxyegre.uniandes.edu.co:8843/article/48659 [Consultado el 16 de octubre de 2018]

BROWN, Wendy, "American Nightmare. Neoliberalism, Neoconservatism and De-democratization" en Political Theory, Vol. 34, no 6, 2006, pp. 690-714.

CEPEDA-MASMELA, Carolina, "¿Dónde Están y Quiénes Son los que Protestan contra la Globalización? Caracterización de las organizaciones participantes en el Foro Social Mundial 2001, 2004 y 2008" en Papel Político, Vol. 21, n 2, 2016, pp. 505-536.

COX, Robert, "Social Forces, States and World Orders Beyond International Relations Theory" en Millennium- Journal of International Relations, Vol. 10, no 2, 1981, pp. 126-155.

CROUCH, Collin, The Strange Non-Death of Neoliberalism, Polity Press, Cambridge, 2011.

DELLA PORTA, Donatella, "The Social Bases of the Global Justice Movement. Some Theoretical Reflections and Empirical Evidence from The First European Social Forum", Working Paper, 2005, www.unrisd.org, consultado en 2008.

DiNerSTEIN, Ana, Movimientos Sociales y Autonomía Colectiva. La Polítia de la Esperanza en América Latina, Capital Intelectual, Buenos Aires, 2013, pp. 21-38.

ESCOBAR, Arturo, Una Minga para el Postdesarrollo: Lugar, Medio Ambiente y Movimientos Sociales en las Transformaciones Globales, Ediciones Desde Abajo, Bogotá D.C., 2012.

EZLN (Ejército Zapatista de Liberación), Palabras de la Comandancia General del EZLN en el Acto de Inicio del Primer Encuentro Interncontinental por la Humanidad y contra el Neoliberalismo, Chiapas, 1996: http://enlacezapatista.ezln.org.mx/1996/07/27/ccri-cg-inicio-del-primer-encuentro-intercontinental-por-la-humanidad-y-contra-el-neoliberalismo/ [Consultado el 12 de octubre de 2018]

FLORINI, Ann, "Who Does What? Collective Action and the Changing Nature of Authority" en BIELER, Andreas, HIGGOTT, Richard \& UNDERHILL, Geoffrey (eds.), Non- State Actors and Authority in the Global System, Routledge, Londres, 2002, pp. 15- 31.

FSM (Foro Social Mundial), Carta de Principios, Port Alegre, 2001: http://fsmm2018.org/carta-de-principios/ [Consultado el 12 de octubre de 2018]

GILL, Stephen, Power and Resistance in the New World Order, Palgrave McMillan, Nueva York, 2008.

GILL, Stephen, "Introduction: Global Crises and the Crisis of Global Leadership" en GILL, Stephen (ed.), Global Crises and the Crisis of Global Leadership, Cambridge University Press, Cambridge, 2012, pp. 21-37.

GILLS, Barry, "Introduction: Globalization and the Politics of Resistance" en GILLS, Barry (ed.), Globalization and the Politics of Resistance MacMillan Press, Londres, 2000, pp. 3-11.

HARVEY, David, Breve Historia del Neoliberalismo, Akal, Madrid, 2007.

HERTZ, Noreena, The Silent Takeover. Global Capitalism and the Death of Democracy, The Free Press, Nueva York, 2001.

KECK, Margaret \& SIKKINK, Kathryn, Activistas Sin Fronteras, Siglo XXI editores, México, 2000.

KLEIN, Naomi, Vallas y Ventanas, Paidós, Barcelona, 2002

KELIN, Naomi, La Doctrina del Shock, Paidós, Buenos Aires, 2010.

MACDONALD, Laura, \& RUCKERT, Arne, "Post-neoliberalism in the Americas: an Introduction" en MACDONALD, Laura, \& RUCKERT, Arne (eds.), Post-neoliberalism in the Americas, Palgrave MacMillan, Londres, 2009, pp. 1-18.

MORTON, Adam David, Unravelling Gramsci: Hegemony and Passive Revolution in the Global Economy, Pluto Press, Londres, 2007, 178-199.

MUÑOZ, Gloria, EZLN: 20 Y 10, El Fuego y La Palabra, La Jornada, México, 2003.

NEGRI, Antonio, Goodbye Mr. Socialism. La Crisis de la Izquierda y los Nuevos Movimientos Revolucionarios, Paidós, Barcelona, 2007, pp. 53-76.

PANEBIANCO, Angelo, Modelos de Partido, Alianza editorial, Madrid, 1982.

PLEYERS, Geoffrey, Alter-Globalization. Becoming Actors in the Global Age, Polity Press, Cambridge, 2010.

POLANYI, Karl, La Gran Transformación: los Orígenes Políticos y Económicos de Nuestro Tiempo, Fondo 
de Cultura Económica, México, 2003, 123-135.

REITAN, Ruth, Global Activism, Routledge, Nueva York, 2007.

RESTREPO, Dario, "De la Falacia Neoliberal a la Nueva Política" en La Falacia Neoliberal. Críticas y Alternativas, Universidad Nacional de Colombia, Bogotá, 2003, pp. 19-40.

ROBERTS, Kenneth. "Beyond Neoliberalism: Popular Responses to Social Change in Latin America" en BURDICK, John, OXHORM, Philip \& ROBERTS, Kenneth (eds.), Beyond Latin America, Societies and Politics at the Crossroads, Palgrave MacMillan, Londres, 2009, pp. 1-13.

RUPERT, Mark, "In the Belly of the Beast: Resisnting Globalisation and War in a Neo-Imperial Moment" en ESCHLE, Catherine \& MAIGUASHCA, Bice (eds.), Critical Theories, International Relations and 'the Anti-Globalisation Movement'. The Politics of Resistance, Routdledge, Nueva York, 2005, pp. 36-52.

SEOANE, José \& TADDEI, Emilio, "De Seattle a Porto Alegre. Pasado, Presente y Futuro del Movimiento Anti-Mundialización Neoliberal" en SEOANE, José \& TADDEI, Emilio (eds.), Resistencias Mundiales de Seattle a Porto Alegre CLACSO, Buenos Aires, 2001, pp. 105- 129.

SIKKINK, Kathryn, "Patterns of Dynamic Multilevel Governance and the Insider-Outsider Coalition" en DELLA PORTA, Donatella \& TARROW, Sidney (eds.), Transnational Protest and Global Activism, Rowman and Littlefield publishers, Nueva York, 2005, pp. 151-173.

SKLAIR, Leslie, Sociología del Sistema Global, Gedisa, Barcelona, 2003.

SMITH, Jackie, "Democratizing Globalization? Impacts and Limitants of Transnational Social Movements" en American Sociological Association Annual Meeting, 2004: http://d-scholarship.pitt. edu/20771/ [Consultado el 16 de octubre de 2018]

STEGER, Manfred, GOODMAN, James, \& WILSON, Erin, Justice Globalism: Ideology, Crisis, Policy, Sage, Londres, 2013.

STEGER, Manfred, \& ROY, Ravi, Neoliberalism: a Very Short Introduction, Oxford University Press, Nueva York, 2010.

STEGER, Manfred, \& WILSON, Erin, "Anti-Globalization or Alter-Globalization? Mapping the Political Ideology of the Global Justice Movement" en International Studies Quarterly, Vol. 56, no 3, 2012, pp. 439-454.

TARROW, Sidney, The New Transnational Activism, Cambridge University Press, Nueva York, 2007.

TARROW, Sidney \& DELLA PORTA, Donatella, "Conclusion: "Globalization", Complex Internacionalism and Transnational Contention" en TARROW, Sidney \& DELLA PORTA, Donatella (eds.), Transnational Protest and Global Activism, Rowman and Lttilefiel publishers, Nueva York, 2005, pp. 227-246.

TEIVAINEN, Teivo, "Global Democratization without Hierarchy or Leadership? The World Social Forum in the Capitalist World" en GILL, Stephen (ed.), Global Crises and the Crisis of Global Leadership, Cambridge University Pres, Londres, 2012, pp. 181-198.

TORMEY, Simon, Anti-Capitalismo: a Beginner's Guide, Oneworld, Oxford, 2004.

WORTH, Owen, Resistance in the Age of Austeriry, Zeld, Londres, 2013, pp. 9-71. 


\section{RELACIONES INTERNACIONALES}

Revista académica cuatrimestral de publicación electrónica Grupo de Estudios de Relaciones Internacionales (GERI) Universidad Autónoma de Madrid, España

www.relacionesinternacionales.info

ISSN 1699 - 3950

ff facebook.com/RelacionesInternacionales

twitter.com/RRInternacional 